\title{
(27) Teil-Zeiten und Zeit Teilen
}

Enrico Danieli

Dr. med., Facharzt für Allgemeine Innere Medizin, Mitglied FMH

Nicht nur das Job-Sharing ist in; alles, was vieles gleichzeitig ermöglicht, ist ein Gebot der Zeit.

Die letzten Vollzeittätigen werden, so die Prognosen, aussterben. Dies ist in keiner Weise zu beklagen. Und, da Ärzten stets Burn-outs drohen, Time-outs zur Regel werden, selbst Work-outs keine Raritäten mehr darstellen, ist es höchste Zeit, Teilzeit-Berufszeiten und deren Reglementierung per Gesetz flächendeckend anzuwenden. Wie wir wissen und wie genügend Studien belegen, ist das Teilzeitarbeitszeitmodul in jedem Sinn sinnvoll, auch oder gerade in der Medizin, denn die Arbeit wird verteilt, der Einzelne leistet mehr in kürzerer Zeit, und das Mehr an Zeit kommt den Kunden zugute. Die zerteilte Praxiszeit ist vielfach sinngebend für Ärztinnen und Mediziner, denn Beruf und Privates, Familie und Hobby werden verträglicher. Belegt ist, dass dank dieses Arbeitszeitsplittings Ehen von Ärztinnen (oder Ärzten) deutlich weniger geschieden werden, und, erfreulich genug, Medizinerinnen mit 1,737 Geburten pro Kopf deutlich über dem hiesigen Gebärschnitt liegen. So gibt es, medizinisch gesehen, keine Argumente gegen solche zeitgemässen Arbeitszeitmodelle, weswegen diese immer häufiger zur Anwendung gelangen in geeigneten Institutionen wie Gruppen-, Gemeinschafts-, Team- und Gemischtgruppenteampraxen.

Als zeitweise Medizinbedürftiger gewöhnt man sich, unter Umständen, an den behandelnden Arzt / an die behandelnde Ärztin. Und umgekehrt. Es entsteht eine Übereinkunft jenseits des Sprachlichen, man ist sich sympathisch, man fühlt sich sicher, im besten Fall verstanden, man weiss, was der andere weiss, und das ist gut so. Das heisst: sich angenommen fühlen. Die Begründungen fürs So-(Anders-)Sein entfallen, Diagnosen und Therapien, wenn auch ausserhalb von Richtlinien, sind/bleiben gültig. Hier, an diesem Punkt, befindet sich die Medizin, verstanden im Sinn vom Dasein für den zeitweise Kranken, in einer Sackgasse. Was gut ist für die Einen, immer beliebter wird (die Berufszeitenteilung), ist für die Anderen ein immenser Verlust an medizinischer Geborgenheit. Dieser Vertrauensverlust lässt sich nicht messen, nicht mit Zahlen belegen. Die lebensdringliche Frage «Wohin mit mir (in medizinischen Belangen)?» stellt sich den Chronikern unter den Kranken immer häufiger und aufs Neue. Gleichzeitig wird von den teilzeitenden Medizinern, wenn überhaupt, mit Erstaunen festgestellt, dass eigentlich nicht Krankheiten zu behandeln wären, sondern (langzeitig) Kranke mit Krankheiten.

Die mich behandelnde Ärztin ist in Urlaub. Fortbildung. Weiterbildung. Ausbildung. Seminar. Kompensation. Überzeit. Auszeit. Nachtzeit. Heirat, Mutter-, Kind-, Familienschaft. Sie ist einfach nicht da! Vieldeutige Auskünfte, nichts Konkretes: Sollte, müsste, könnte, vielleicht. Hinzu kommt, ein Nachteil der Teilzeit, dass meine Krankheit sich nicht an den einen Dienstag in der Woche hält. Von einer kontinuierlichen Behandlung kann keine Rede mehr sein. Und: Darf man sagen, dass nicht alle, die mich nun ersatzmässig zu behandeln haben, sympathisch sind, gelegentlich mehr als wenig sympathisch? Und ich als Patient, der üblicherweise bei der Abwesenden in Behandlung steht, störe nur. Grosszügig hat man mich («nur kurz!» «pumpenvoll») noch hineingedrückt. Nachlässig schaut man die Daten an, stellt zum hundertsten Mal die gleichen Fragen, ist nicht bei der Sache, weil mein Fall eh der Anderen gehört. Man verfügt über alle Daten, doch diese sind zu viel, ein kurzes stummes Computerspiel: alles ist schliesslich allen alles. Verwiesen wird auf neuere Studien, will nun das, was nicht studienmässig bewiesen ist, abändern, umstellen; alles, was nicht zeitgemäss ist, entsorgen: Medikamente, mich. So führt mich meine Abwesende in den Abgrund, schuldlos. Und ich ziehe weiter von Doktor zu Doktor. Man versteht nichts und tut doch so, als wüsste man alles besser. Und werde verschoben, ein Gepäckstück: Von da nach dort, extern, intern, von oben nach unten, und jene unten wissen nichts von denen oben ad infinitum ...

Wir lieben die Teilzeit, denken an uns, nichts als an uns, und vergessen, dass Krankheiten zu Kranken gehören, die sich nicht an unser Teilzeitfreizeitidealarbeitsschemamodul halten. Gefühle von Ratlosigkeit, Hilflosigkeit, Machtlosigkeit begleiten nun meine Arztbesuche. Dass ich einmal so viel Mühe haben werde mit «meiner» Medizin, habe ich mir nicht im Traum vorgestellt. Da ist er, einer meiner Leitsprüche: alles wird schlechter, nichts bleibt - schlecht.

Bildnachweis

(c) Erllre | Dreamstime.com 